\title{
Cystoid macular oedema following cataract extraction in patients with diabetes
}

\author{
A Pollack, H Leiba, A Bukelman, $M$ Oliver
}

\begin{abstract}
The course of cystoid macular oedema (CMO) following extracapsular cataract extraction with posterior chamber intraocular lens implantation was prospectively studied in 44 eyes of 44 consecutive diabetic patients without preoperative CMO. In $\mathbf{5 0 \%}$ of eyes CMO was observed 6 weeks after surgery and in $25 \%$ was still present at 1 year. The preoperative presence of diabetic retinopathy significantly affected the postoperative onset and persistence of CMO. CMO occurred postoperatively in only $32 \%$ of eyes without pre-existing diabetic retinopathy and in $81 \%$ of eyes with pre-existing diabetic retinopathy $(p<0.05)$. CMO persisted at 1 year after surgery in only $7 \%$ of eyes without pre-existing diabetic retinopathy and in $56 \%$ of eyes in which diabetic retinopathy persisted $(\mathbf{p}<0.01)$. Angiographic CMO (that is, detectable only on fluorescein angiography) was more common than clinical CMO (detectable on ophthalmoscopic examination as well) in eyes with no pre-existing diabetic retinopathy, whereas clinical CMO was seen more often than angiographic CMO when diabetic retinopathy was present preoperatively $(\mathbf{p}<0.01)$. The course and final visual outcome of angiographic CMO were more favourable than in clinical CMO. Final visual acuity of at least 6/12 was achieved in $86 \%$ of eyes with angiographic CMO and in only $33 \%$ of eyes with clinical CMO. On the basis of the above findings we believe that cataract extraction should not be recommended for eyes with pre-existing diabetic retinopathy until the vision has deteriorated to at least $6 / 30-6 / 60$.
\end{abstract}

The visual prognosis following cataract surgery in diabetic patients depends on the presence and/ or the severity of existing diabetic retinopathy and its possible aggravation after surgery. ${ }^{1-6}$ In particular the visual outcome may be influenced by the postoperative onset of cystoid macular oedema (CMO) which may occur even without onset or aggravation of diabetic retinopathy.

In a previous study we observed a high incidence of progression of diabetic retinopathy following cataract surgery.' 'Progression' was defined as appearance or worsening of the diabetic retinopathy regardless of whether or not CMO was present. However though that study did not deal specifically with the course of maculopathy our clinical impression was that the presence of CMO after cataract extraction is more common in diabetic than in non-diabetic eyes.

The purpose of this prospective study was to investigate the onset and course of CMO following cataract surgery with lens implantation in diabetic patients. The diabetic patients in this study all underwent extracapsular cataract extraction with posterior chamber lens implantation and did not have CMO prior to surgery.

\section{Subjects and methods}

Included in this study were 44 eyes of 44 consecutively diabetic patients, with or without diabetic retinopathy who underwent extracapsular cataract extraction with posterior chamber intraocular lens implantation in our department between January 1987 and January 1990 and who met the following criteria: (1) diagnosis of diabetes mellitus at least 6 months prior to cataract surgery; (2) uneventful surgical procedure, performed by a team of senior specialists in cataract surgery; (3) no evidence of CMO prior to surgery or, where the cataract had precluded visualisation of the fundus preoperatively, within the first 3 days after surgery; (4) no laser treatment for diabetic retinopathy given or required before or within 1 month after surgery. This restricts the series to eyes in which diabetic retinopathy if present at the time of surgery, was of the mild non-proliferative type; (5) no other ocular disorders; (6) postoperative follow-up for at least 1 year; (7) a fundal examination prior to and/or within 3 days after surgery as a baseline for postoperative assessment of retinal status; (8) additional fundal examinations during three distinct periods within the first year of postoperative follow-up: (a) from the second week to the end of the third month; (b) from the fourth to the end of the sixth month; and (c) from the seventh to the end of twelfth month.

All patients underwent routine fluorescein angiography 6 weeks and 6 months after surgery. In those cases where onset or progression of diabetic retinopathy had occurred and/or fluorescein angiography revealed persistence of $\mathrm{CMO}$ after 6 months additional angiograms were obtained every 2 months until the end of the study, which was 1 year after surgery. In cases where CMO was not demonstrated initially on the angiogram but was suspected on the basis of an ophthalmoscopic examination angiography was repeated. Fundal examinations, colour fundal photography, and fluorescein angiography readings were performed by a retinal specialist.

After surgery if the severity of diabetic retinopathy and/or macular oedema met the criteria for treatment as outlined by the Diabetic Retinopathy and Early Treatment Diabetic Retinopathy Studies argon laser photocoagulation was performed in accordance with their recommendations. ${ }^{89}$ Laser treatment consisted of panretinal photocoagulation for proliferative or very

\section{Dr A Pollack, Department of Ophthalmology, Kaplan Hospital, 76100 Rehovot, Accepted for publication \\ 29 August 1991

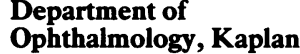 A Pollack \\ H Leiba}


Table 1 Clinical features of diabetic and non-diabetic patients with and without CMO and control patients following cataract surgery

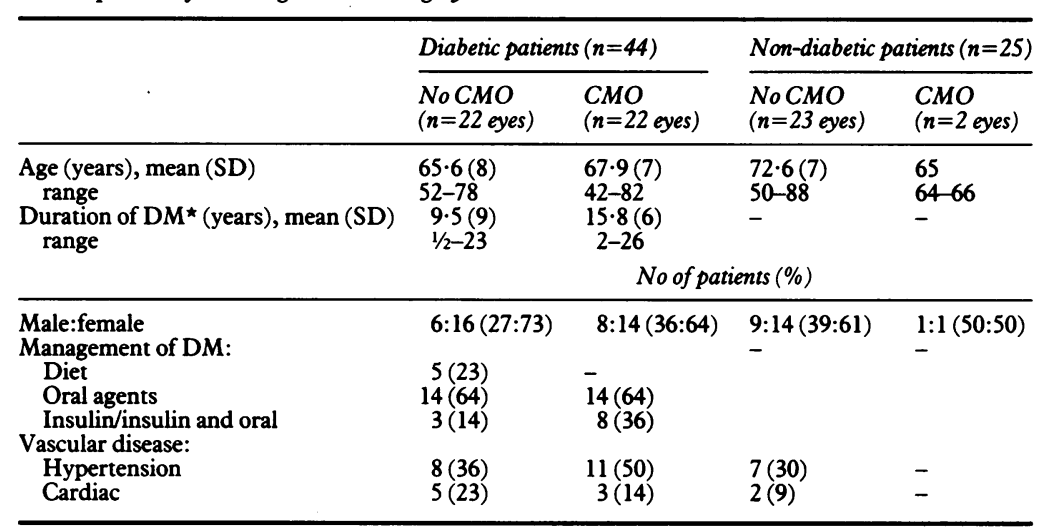

^Diabetes mellitus. with no pre-existing diabetic retinopathy developed either non-proliferative diabetic retinopathy or proliferative diabetic retinopathy after surgery; or (2) a patient with pre-existing non-proliferative diabetic retinopathy showed postoperative aggravation of the non-proliferative changes or development of proliferative diabetic retinopathy as previously described by us. ${ }^{5}$

The control group consisted of 25 eyes of 25 consecutive non-diabetic patients who underwent the identical surgical procedure performed by the same surgical team during the same period and who met our inclusion criteria nos. 2 and 5-8 listed above.

The $\chi^{2}$ test was used for statistical analysis.

\section{Results}

severe non-proliferative diabetic retinopathy and/or focal or grid argon green laser photocoagulation for macular oedema. ${ }^{89}$

For each patient a standardised medical protocol was completed giving detailed demographic and clinical information including duration of diabetes mellitus, presence of other systemic diseases, and medications. The ocular findings recorded during each follow-up period included best corrected visual acuity, applanation tonometry, biomicroscopy, Goldman threemirror examination, and indirect ophthalmoscopy; also recorded were the findings of preand postoperative fluorescein angiography and the results of laser treatment.

Cystoid macular oedema was diagnosed as angiographic if fluorescein angiography revealed the typical appearance of CMO as described by Gass and Norton, ${ }^{10}$ and as clinical if CMO was demonstrated on both fluorescein angiography and fundal examination.

On the basis of the macular findings eyes were divided into three groups: eyes that did not develop CMO, eyes with angiographic CMO only, and eyes with clinical CMO. On the basis of the diabetic retinal findings two subgroups were identified. The first, defined as the 'no change' subgroup consisted of eyes in which the retinal status remained unchanged following surgery regardless of whether or not diabetic retinopathy was present preoperatively. The second, termed the 'progression' subgroup, consisted of eyes in which diabetic retinopathy first appeared or progressed following surgery. Progression was considered to have occurred when: (1) a patient

Table 2 Postoperative development of clinical and angiographic CMO in relation to the preoperative status of diabetic retinopathy

\begin{tabular}{|c|c|c|c|}
\hline \multirow[b]{3}{*}{ Preoperative status: } & \multicolumn{3}{|c|}{$\begin{array}{l}\text { Postoperative development of CMO } \\
\text { ( } n=44 \text { eyes) }\end{array}$} \\
\hline & $\begin{array}{l}\text { Angiographic } \\
C M O \neq \\
7(16 \%)\end{array}$ & $\begin{array}{l}\text { Clinical } \\
\text { CMOS } \\
15(34 \%)\end{array}$ & $\begin{array}{l}\text { Total } \\
22(50 \%)\end{array}$ \\
\hline & \multicolumn{3}{|c|}{ No of eyes/total (\%) } \\
\hline $\begin{array}{l}\text { No } \mathrm{DR}^{\star}(n=28 \text { eyes }) \\
\operatorname{DR} t(n=16)\end{array}$ & $\begin{array}{l}6 / 28(21) \\
1 / 16(6) \\
p<0.01\end{array}$ & $\begin{array}{r}3 / 28(11) \\
12 / 16(75)\end{array}$ & $\begin{array}{r}9 / 28(32) \\
13 / 16(81)\end{array}$ \\
\hline
\end{tabular}

^No diabetic retinopathy; †Diabetic retinopathy; $¥$ Angiographic CMO only; OPhthalmoscopic and angiographic CMO. men and 30 were women. The mean age at the time of surgery was 66.7 years (range 42 to 82 ) and the mean duration of diabetes mellitus was 12.6 years (range 6 months to 26 years). Cataract extraction was unilateral in 36 patients and bilateral in eight. In the bilateral cases only one eye, the one operated on first, was included in the study. Of the 25 patients in the control group 10 were men and 15 were women. Their mean age at the time of surgery was $71 \cdot 2$ years (range 50 to 88) (Table 1).

Following surgery 22 eyes in the study group (50\%) developed CMO compared with two eyes (8\%) in the control. Table 1 compares the clinical features of patients with and without postoperative onset of CMO. Differences between patients in this respect were not significant though patients with CMO had diabetes mellitus of longer duration than those without $\mathrm{CMO}$, and more patients in the group with CMO needed insulin.

Clinical CMO was diagnosed in 15 eyes in the study group (34\%) and angiographic CMO only in seven (16\%). The corresponding findings in the control group were one eye $(4 \%)$ in each category; the angiographic CMO subsequently disappeared but the clinical CMO persisted. The relationship between the preoperative diabetic retinal status and the onset of clinical or of angiographic CMO in the 22 study group eyes that developed CMO is summarised in Table 2 . The relationship between the preoperative diabetic retinal status and the postoperative course of diabetic retinopathy and of CMO is presented in Table 3. Table 4 summarises the incidence of CMO and its persistence 1 year after surgery in relation to both the preoperative and the postoperative status of diabetic retinopathy.

Of the 13 eyes with preoperative diabetic retinopathy and postoperative onset of CMO, nine also showed progression of diabetic retinopathy following surgery. Five of these 13 eyes received laser treatment for their postoperative retinopathic changes and eight did not. In the nine eyes that had no diabetic retinopathy preoperatively and developed CMO postoperatively laser treatment was not indicated (Table 4).

Table 5 compares the final visual acuity results in diabetic patients with and without postoperative onset of CMO. In both cases more patients
Of the 44 patients in the study group 14 were 
Table 3 Postoperative course of diabetic retinopathy and onset of CMO in relation to the preoperative status of diabetic retinopathy

\begin{tabular}{|c|c|c|c|c|}
\hline \multirow[b]{3}{*}{ Preoperative status } & \multicolumn{4}{|c|}{$\begin{array}{l}\text { Postoperative status of diabetic retinopathy } \\
\text { ( } n=44 \text { eyes) } \\
\text { No of eyes }(\%)\end{array}$} \\
\hline & \multicolumn{2}{|c|}{$\begin{array}{l}\text { No change of } D R \\
26(59)\end{array}$} & \multicolumn{2}{|c|}{$\begin{array}{l}\text { Progression of } D R \\
18(41)\end{array}$} \\
\hline & $\begin{array}{l}\text { Without } \\
\text { CMO } \\
18(69)\end{array}$ & $\begin{array}{l}\text { With } \\
\text { CMO } \\
8(31)\end{array}$ & $\begin{array}{l}\text { Without } \\
\text { CMO } \\
4(22)\end{array}$ & $\begin{array}{l}\text { With } \\
\text { CMO } \\
14(78)\end{array}$ \\
\hline $\begin{array}{l}\text { No } \operatorname{DR}^{\star}(n=28 \text { eyes }) \\
\operatorname{DR}+(n=16 \text { eyes })\end{array}$ & $\begin{array}{l}17 / 28(61) \\
1 / 16(6) \\
p<0\end{array}$ & $\begin{array}{l}4 / 28(14) \\
4 / 16(25) \\
.025\end{array}$ & $\begin{array}{l}2 / 28(7) \\
2 / 16(13)\end{array}$ & $\begin{array}{l}5 / 28(18) \\
9 / 16(56) \\
\end{array}$ \\
\hline
\end{tabular}

^No diabetic retinopathy.

tDiabetic retinopathy.

NS, not significant.

achieved a final vision of at least $6 / 12$ if there was no diabetic retinopathy prior to surgery. As shown in Table 6 the visual acuity results were better in patients with angiographic than with clinical CMO. In our control group the visual acuity results of eyes that did not develop CMO were similar to those of the diabetic patients with non-pre-existing diabetic retinopathy and no CMO. The eye with persistent CMO had a final visual acuity of $6 / 30$.

\section{Discussion}

None of the diabetic patients in this series had CMO prior to cataract surgery but $50 \%$ (22 eyes) developed it postoperatively. The occurrence of CMO after surgery in these eyes could have been a consequence of the operation itself (pseudophakic CMO) or of postoperative deterioration of diabetic retinopathy (diabetic CMO), or both. Since it was not possible to distinguish between them all cases of CMO were included in our analysis of the results.

Our definition of CMO as 'angiographic' in this study was based on typical findings on fluorescein angiography as described by Gass and Norton. ${ }^{10}$ After cataract surgery a diagnosis of clinical CMO is usually based not only on typical angiographic findings but also on poor visual acuity $(<6 / 12)^{11}$; however, we considered visual acuity to be an unreliable criterion here as our cases included eyes with diabetic retinopathy, itself a possible factor affecting visual acuity. We therefore diagnosed CMO as 'clinical' on the basis of ophthalmoscopic (in addition to angiographic) findings.

In non-diabetic eyes angiographic CMO fol- lowing extracapsular cataract extraction with posterior chamber lens implantation reportedly occurs in as many as $44 \%$ of cases. ${ }^{12}$ In our control group it occurred in only $8 \%(2 / 25)$ compared with an incidence of $50 \%$ in the diabetic eyes. It should be noted however that the occurrence of CMO in the diabetic eyes appeared to be influenced by the pre- or postoperative diabetic retinal status and especially by the former: it occurred in $81 \%(13 / 16)$ of eyes that had pre-existing diabetic retinopathy and in only $32 \%(9 / 28)$ of eyes that did not. Since preexisting diabetic retinopathy is also a risk factor for its postoperative aggravation, ${ }^{7}$ which may be associated with $\mathrm{CMO}$, it is possible that the preexistence of diabetic retinopathy may have contributed to the postoperative development of CMO. In this study most of the eyes with postoperative progression of diabetic retinopathy also developed CMO (78\%, 14/18), whether diabetic retinopathy had pre-existed $(82 \%, 9 / 11)$ or not $(71 \%, 5 / 7)$ (Table 3$)$.

In the general population CMO, if it appears at all after surgery, usually occurs within 6 weeks of the operation, is transitory, and disappears within 6 months. " The reported incidence of CMO persisting for 6 months after surgery ranges between 0.9 and $4 \% .{ }^{11} 13-15$ In our control group it persisted in $4 \%$. In the diabetic group however CMO lasted longer and was still evident even after 6 months. We therefore considered CMO as 'persistent' if it was still present at 1 year after surgery (Table 4). Persistence of CMO was noted in $25 \%$ of the diabetic eyes and like the postoperative incidence of CMO in these eyes varied with the preoperative retinal status (see Table 4). If we assume that persistence of CMO for at least 1 year after surgery in diabetic patients is equivalent to its persistence for at least 6 months in the general population then our diabetic patients with no pre-existing diabetic retinopathy did not differ significantly from our control group in this regard $7 \% v 4 \%$ respectively). Eyes with pre-existing diabetic retinopathy that progressed after surgery $(89 \%, 8 / 9)$ carried the highest risk of persistence.

Visual acuity of at least $6 / 12$ was achieved by a high percentage of eyes that developed angiographic CMO after surgery, similar to the percentage in the subgroup of operated patients with no pre-existing diabetic retinopathy and no CMO (Table 5, 6). Similar findings have been reported by others. ${ }^{12}$ In eyes that developed clinical CMO the visual acuity outcome was less favourable, especially in the subgroup with pre-

Table 4 Postoperative course of CMO in relation to pre- and postoperative status of diabetic retinopathy

\begin{tabular}{|c|c|c|c|c|c|c|c|c|c|}
\hline \multirow[b]{3}{*}{ Preoperative status } & \multicolumn{9}{|c|}{$\begin{array}{l}\text { Postoperative course of CMO ( } n=22 \text { eyes }) \\
\text { No of eyes/total }(\%)\end{array}$} \\
\hline & \multicolumn{3}{|c|}{$C M O$ with no change of $D R$} & \multicolumn{3}{|c|}{$C M O$ with progression of $D R$} & \multicolumn{3}{|l|}{ Total } \\
\hline & $\begin{array}{l}\text { Appearance } \\
(n=8)\end{array}$ & $\begin{array}{l}\text { Persistence } \\
\text { after } 6 \text { months } \\
(n=8)\end{array}$ & $\begin{array}{l}\text { Persistence } \\
\text { after I year } \\
(n=2)\end{array}$ & $\begin{array}{l}\text { Appearance } \\
(n=14)\end{array}$ & $\begin{array}{l}\text { Persistence } \\
\text { after } 6 \text { months } \\
(n=12)\end{array}$ & $\begin{array}{l}\text { Persistence } \\
\text { after l year } \\
(n=9)\end{array}$ & $\begin{array}{l}\text { Appearance } \\
(n=22)\end{array}$ & $\begin{array}{l}\text { Persistence } \\
\text { after } 6 \text { months } \\
(n=20)\end{array}$ & $\begin{array}{l}\text { Persistence } \\
\text { after } 1 \text { year } \\
(n=11)\end{array}$ \\
\hline $\begin{array}{l}\text { No DR* } \\
\text { DR } \dagger\end{array}$ & $\begin{array}{l}(n=21) 4 / 21 \\
(n=5) \\
4 / 5 \ddagger\end{array}$ & $\begin{array}{l}4 / 21 \\
4 / 5\end{array}$ & $\begin{array}{l}1 / 21 \\
1 / 5\end{array}$ & $\begin{array}{l}(n=7) 5 / 7 \\
(n=11) 9 / 11 \oint\end{array}$ & $\begin{array}{l}3 / 7 \\
9 / 11\end{array}$ & $\begin{array}{l}1 / 7 \\
8 / 11\end{array}$ & $\begin{array}{ll}(n=28) & 9 / 28(32) \\
(n=16) & 13 / 16(81) \\
\text { Total: } & 22 / 44 \\
& \mathrm{p}<0.05\end{array}$ & $\begin{array}{r}7 / 28(25) \\
13 / 16(81) \\
20 / 44(45)\end{array}$ & $\begin{array}{c}2 / 28(7) \\
9 / 16(56) \\
11 / 44(25) \\
p<0.01\end{array}$ \\
\hline
\end{tabular}

$\star$ No diabetic retinopathy; $†$ Diabetic retinopathy; $¥$ Argon laser treatment was applied in two cases: in one the CMO resolved and in the other it persisted; $₫$ Argon laser treatment was applied in three cases: in all of them CMO persisted. 
Table 5 Comparison of visual acuity results in diabetic eyes with and without $C M O$ after cataract surgery in relation to preoperative status of diabetic retinopathy

\begin{tabular}{|c|c|c|c|c|c|c|}
\hline \multirow[b]{3}{*}{ Visual acuity } & \multicolumn{3}{|c|}{$\begin{array}{l}\text { Without } C M O \\
(n=22 \text { eyes })\end{array}$} & \multicolumn{3}{|c|}{$\begin{array}{l}\text { With CMO } \\
\text { ( } n=22 \text { eyes })\end{array}$} \\
\hline & $\begin{array}{l}\text { No DRR } \\
(n=19)\end{array}$ & $\begin{array}{l}D R t \\
(n=3)\end{array}$ & $\begin{array}{l}\text { Total } \\
(n=22)\end{array}$ & $\begin{array}{l}\text { No } D R \\
(n=9)\end{array}$ & $\begin{array}{l}D R \\
(n=13)\end{array}$ & $\begin{array}{l}\text { Total } \\
(n=22)\end{array}$ \\
\hline & No $(\%)$ & & & & & \\
\hline $\begin{array}{l}>6 / 12 \\
6 / 15-6 / 30 \\
<6 / 30\end{array}$ & $\begin{array}{r}16(84) \\
3(16) \\
-\quad\end{array}$ & $\begin{array}{l}\overline{2}(67) \\
1(33)\end{array}$ & $\begin{array}{c}16(73) \\
5(23) \\
1(4)\end{array}$ & $\begin{array}{l}6(67) \\
3(33) \\
-\end{array}$ & $\begin{array}{l}5(38) \\
8(62) \\
-\end{array}$ & $\begin{array}{l}11(50) \\
11(50) \\
-\end{array}$ \\
\hline
\end{tabular}

^No diabetic retinopathy.

† Diabetic retinopathy.

Table 6 Visual acuity results in diabetic eyes with clinical and angiographic CMO following cataract surgery in relation to preoperative status of diabetic retinopathy

\begin{tabular}{|c|c|c|c|c|c|c|}
\hline \multirow[b]{3}{*}{ Visual acuity } & \multicolumn{3}{|c|}{$\begin{array}{l}\text { Angiographic } C M O \ddagger \\
\text { ( } n=7 \text { eyes })\end{array}$} & \multicolumn{3}{|c|}{$\begin{array}{l}\text { Clinical CMOS } \\
(n=15 \text { eyes })\end{array}$} \\
\hline & $\begin{array}{l}\text { No } D R^{\star} \\
(n=6)\end{array}$ & $\begin{array}{l}D R t \\
(n=1)\end{array}$ & $\begin{array}{l}\text { Total } \\
(n=7)\end{array}$ & $\begin{array}{l}\text { No DR } \\
(n=3)\end{array}$ & $\begin{array}{l}D R \\
(n=12)\end{array}$ & $\begin{array}{l}\text { Total } \\
(n=15)\end{array}$ \\
\hline & No(\%) & & & & & \\
\hline $\begin{array}{l}\geq 6 / 12 \\
6 / 15-6 / 30 \\
<6 / 30\end{array}$ & $\begin{array}{l}5(83) \\
3(17) \\
-\end{array}$ & $\begin{array}{l}1(100) \\
- \\
-\end{array}$ & $\begin{array}{l}6(86) \\
1(14) \\
-\end{array}$ & $\begin{array}{l}2(67) \\
1(50) \\
-\end{array}$ & $\begin{array}{l}3(25) \\
9(75) \\
-\end{array}$ & $\begin{array}{r}5(33) \\
10(67) \\
-\end{array}$ \\
\hline
\end{tabular}

$\star$ No diabetic retinopathy.

† Diabetic retinopathy.

$\neq$ Angiographic CMO only.

§Ophthalmoscopic and angiographic appearance of CMO.

existing diabetic retinopathy where $75 \%$ of patients achieved vision of only $6 / 15$ to $6 / 30$. Thus the visual prognosis in patients with clinical CMO is worse than in those with angiographic CMO. In eyes with no pre-existing diabetic retinopathy angiographic CMO was more common than clinical CMO (21\% v $11 \%$, Table 2). It resolved spontaneously with 1 year, it persisted only slightly more frequently than in the general population ( $7 \% v 4 \%)$, and its final visual acuity was good. In contrast, eyes with pre-existing diabetic retinopathy were more likely to develop clinical CMO $(75 \% v 6 \%$, Table 2), which has a relatively high tendency (56\%) to persist for more than 1 year of follow-up.

Questions arise as to whether the lens implant increases the inflammatory reaction in the eyes of diabetic patients relative to those of non-diabetic patients, and whether diabetic patients with lens implants have more macular oedema than those without them. Many authors believe nowadays that diabetic patients need not be excluded from the optical advantages of intraocular lenses especially as in diabetics the optical disadvantages of peripheral field constriction and distortion with aphakic spectacle correction are intensified in the presence of macular disease and panretinal photocoagulation. ${ }^{16}$ Correction by contact lens in diabetic patients is often complicated by recurrent corneal erosion. ${ }^{17}$ These questions should be addressed in randomised clinical trials of cataract surgery with and without intraocular lens implantation in diabetic and non-diabetic patients.

The results of this study indicate that after cataract surgery with lens implantation CMO occurs more often and persists for longer in eyes of diabetic than of non-diabetic patients. In addition it is affected by the preoperative retinal status. Eyes with no pre-existing diabetic retinopathy tend to develop angiographic rather than clinical CMO; this seldom persists for longer than 1 year and the final visual outcome resembles that of the general population. In contrast operated eyes with pre-existing diabetic retinopathy tend to develop clinical CMO, which quite often persists for at least 1 year, and the final visual acuity can be expected to be in the range of $6 / 15-6 / 30$. These findings may act as guidelines when cataract surgery is contemplated for diabetic patients. We would counsel a cautious approach for eyes with pre-existing diabetic retinopathy; surgery should probably not be recommended in such cases until vision has deteriorated to at least $6 / 30-6 / 60$.

A Pollack and M Oliver are affiliated with the Hebrew University, Hadassah Medical School, Jerusalem, Israel.

1 Kirmani TH. Prognosis of cataract extraction in diabetes. Am F Ophthalmol 1964; 57: 617-9.

2 Clayman HM, Jaffe NS, Light DS. Lens implantation and diabetes mellitus. Am F Ophthalmol 1979; 88: 990-2.

3 Apple DJ, Mamalis N, Loftfield K, et al. Complications of intraocular lenses. A historical and histopathological review. Surv Ophthalmol 1985; 29: 1-54.

4 Jaffe GJ, Burton TC. Progression of nonproliferative diabetic retinopathy following cataract extraction. Arch Ophthalmol 1988; 106: 745-9.

5 Pollack A, Dotan S, Oliver $M$. Course of diabetic retinopathy following cataract surgery. Br $\mathcal{F}$ Ophthalmol 1991; 75: 2-8.

6 Cunliffe IA, Flanagan DW, George NDL, Aggarwaal RJ, Moore AT. Extracapsular cataract surgery with lens imMoore AT. Extracapsular cataract surgery with lens implantation in diabetics with and without

7 Pollack A, Dotan S, Oliver M. Progression of diabetic retinopathy after cataract extraction. Br f Ophthalmol 1991; 75: 547-51.

8 The Diabetic Retinopathy Study Research Group. Preliminary report on effects of photocoagulation therapy. Am F Ophthalmol 1976; 81: 383-96.

9 Early Treatment Diabetic Retinopathy Study Research Group. Treatment techniques and clinical guidelines for photocoagulation of diabetic macular edema: Early Treatment Diabetic Retinopathy Study Report Number 2. Ophthalmology 1987; 94: 761-74.

10 Gass JDM, Norton EWD. Cystoid macular edema and papilledema following cataract extraction: a fluorescein funduscopic and angiographic study. Arch Ophthalmol 1966; 76: 646-61.

11 Stark WK, Maumenee AE, Fagadau W, et al. Cystoid macular edema in pseudophakia. Surv Ophthalmol 1984; 28: 442-51.

12 Kraff MC, Sanders DR, Jampol LM, et al. Effect of an Kraff MC, Sanders DR, Jampol LM, et al. Effect of an
ultraviolet-filtering intraocular lens on cystoid macular ultraviolet-filtering intraocular lens on

13 The Miami Study Group. Cystoid macular edema in aphakic and pseudophakic eyes. Am $\mathcal{F}$ Ophthalmol 1979; 88: 45-8.

14 Wetzig PC, Thatcher DB, Christiansen JM. The intracapsular versus the extracapsular cataract technique in relationship to retinal problems. Trans Am Ophthalmol Soc 1979; 77: 339-47.

15 Chambless WS. Phacoemulsification and the retina; cystoid macular edema. Ophthalmology 1979; 86: 2019-22.

16 Kokame GT, Flynn HW Jr, Blankeship GW. Posterior chamber intraocular lens implantation during diabetic pars plana vitrectomy. Ophthalmology 1989; 96: 603-10.

17 Schultz RO, Van Horn DL, Peters MA, Klewin KM, Schutten WH. Diabetic keratopathy. Trans Am Ophthalmol Soc 1981; 79: 180-99. 